\title{
Memahami Kebijakan Redaksional Rubrik Pendidikan Di Surat Kabar Harian Solopos
}

\author{
Sri Wulan \\ (Sriwulan@yahoo.com) \\ Alumni Ilmu Komunikasi FTIK USM
}

\begin{abstract}
This study aims to understand how the framing of news is created in the education section of daily newspapers SOLOPOS. The main theory used in this research is the analysis of Todd Gitlin framing. With frames, journalist processing a wide range of information available to the pack in such a way in certain cognitive categories and presented to the audience. The methodology used is qualitative descriptive and analytical approach to framing using Todd Gitlin. This research was conducted at PT. AKSARA SOLOPOS Jl. Adisucipto No. Solo 19057 145, with two (2) of informants in accordance with the criteria of the study subjects. The object of research is selected Pawiyatan money news relating to the acceptance of new students high school / vocational equivalent which in its message has content related message new admissions in July 2014. It was concluded from this study, education rubric SOLOPOS daily newspapers in reporting the news focus close to Solo and the surrounding community. The existence of sub-sections that are inserted every day to differentiate with other newspapers.
\end{abstract}

Kata Kunci: Rubrik Pendidikan, Framing, Berita Pawiyatan

\section{Pendahuluan}

Ada beberapa surat kabar di Jawa Tengah, khususnya surat kabar lokal, salah satunya adalah SOLOPOS. Sebagai surat kabar lokal, SOLOPOS berusaha mengakomodasikan berbagai kepentingan yang ada di masyarakat, mulai dari sosial, budaya, ekonomi dan politik. SOLOPOS juga berusaha menempatkan dirinya sebagai koran yang dapat memenuhi kebutuhan masyarakat

Dari beberapa berita yang dimuat di rubik pendidikan surat kabar harian SOLOPOS, terlihat beberapa keunikan pada karakteristik isi berita di rubrik pendidikan. Setiap hari isi berita yang muat selalu disisipkan berita-berita tambahan yang bersifat soft news, seperti pawiyatan.
Berbeda dengan surat kabar lain seperti WAWASAN, isi berita di rubrik pendidikan tidak ada konsitensi isi berita seperti yang terdapat di surat kabar harian SOLOPOS. Dalam pemberitaannya, SOLOPOS fokus pada wilayah-wilayah Kota Solo dan sekitarnya.

Sub rubrik pawiyatan adalah salah satu sub rubrik yang isi beritanya mencakup kelebihan non akademik yang terdapat di lembaga pendidikan misalnya prestasi dan kegiatan yang memiliki keunikan, keunggulan sekolah yang berbeda dengan sekolah lain. Hal ini menarik untuk diteliti lebih lanjut bagaimana SOLOPOS menyajikan dan membingkai (framing) berita terkait dengan isi berita pada sub rubrik pawiyatan di rubrik pendidikan surat 
kabar harian SOLOPOS pada bulan Juli 2014 tepatnya saat mendekati penerimaan siswa baru.

Hal ini menarik untuk diteliti lebih lanjut bagaimana SOLOPOS menyajikan dan membingkai (framing) berita terkait dengan isi berita pada rubrik pendidikan surat kabar harian SOLOPOS pada bulan Juli 2014 tepatnya saat mendekati penerimaan siswa baru.

Penelitian ini mengkaji analisis framing dari Todd Gitlin. Pada penelitian ini, peneliti lebih mendalami tentang keunikan isi berita bersifat soft news yang terdapat di berita pawiyatan pada rubrik pendidikan di surat kabar harian SOLOPOS terutama bagaimana membingkai berita soft new saat mendekati penerimaan siswa baru . Penelitian sejenis sebelumnya juga pernah dilakukan oleh Umi Maspiah dengan judul penelitian "Analisis Framing Iklan Politik "Indonesia Hebat" Partai Demokrasi Indonesia Perjuangan (PDIP) Pada Pemilu Tahun 2014 Di Media Televisi ". Perbedaan dari penelitian sebelumnya yaitu penelitian ini lebih mendalami tentang isi berita bersifat soft news sub rubrik pawiyatan yang terdapat pada rubrik pendidikan di surat kabar harian SOLOPOS.

Analisis framing menyediakan teori dan metode yang dapat digunakan untuk mengetahui bagaimana realitas dikonstruksi oleh media, bagaimana wartawan mengkonstruksi peristiwa dan menyajikannya kepada khalayak pembaca.

Salah satu pembeda isi sebuah surat kabar yaitu rubrik. Rubrik adalah kepala karangan (ruang tetap) dalam media cetak baik surat kabar maupun majalah.

\section{Tinjauan Pustaka}

\section{Pengertian Berita}

Berita merupakan laporan atau informasi aktual berisi tentang faktafakta dan opini yang menarik perhatian orang. Informasi hangat tentang sesuatau yang telah terjadi ataupun perisatiwa yang belum diketahui sebelumnya. Suatu peristiwa dapat disebut berita apabila sudah disiarkan dalam sebuah media massa, semisal media cetak atau surat kabar. (Budyatno,2009:39). Morrisan membagi berita menjadi dua, yaitu:

\subsection{Hard news}

Hard news adalah segala informasi penting atau menarik yang harus segera disiarkan oleh media penyiaran karena sifatnya yang harus segera ditayangkan agar dapat diketahui khalayak audien secepatnya seperti breaking news, bulletin, spot news dan straight news termasuk dalam hard news (Morissan, 2008 : 25).

\subsection{Soft News}

Soft news adalah segala informasi yang penting dan menarik yang disampaikan secara mendalam (indepth) namun tidak bersifat harus segera ditayangkan. Berita yang masuk kategori ini ditayangkan pada satu program tersendiri di luar program berita. Yang termasuk dari soft news adalah feature, documenter, dan talkshow (Morissan, 2008 : 27).

\section{Analisis Framing Todd Gitlin}

Gitlin mengemukakan dua aspek dalam framing:

1. Memilih fakta/realitas, dalam memilih fakta selalu terkandung dua 
kemungkinan yaitu apa yang dipilih (included) dan apa yang dibuang (exluded). Akibatnya, pemahaman dan konstruksi atas suatu peristiwa bisa jadi berbeda antara satu media dengan media lain.

2. Menuliskan fakta, Proses ini berhubungan dengan bagaimana fakta yang dipilih disajikan kepada khalayak. Bagaimana fakta yang sudah dipilih tersebut ditekankan dengan pemakaian perangkat tertentu: penempatan yang mencolok (headline depan, atau belakang), pengulangan, pemakaian grafis untuk mendukung dan memperkuat penonjolan, pemakaian label tertentu ketika menggambarkan orang/peristiwa yang diberitakan, asosiasi terhadap simbol budaya, generalisasi, simplifikasi, dan pemakaian kata yang mencolok, gambar, dan sebagainya. Akibatnya, aspek tertentu yang ditonjolkan menjadi menonjol, lebih mendapatkan alokasi dan perhatian yang besar dibandingkan aspek lain.

\section{Pembahasan}

Ada dua hal yang dapat disimpulkan dari hasil penelitian yang sudah dijelaskan. Pertama, bagaimana realitas/dunia dibentuk dilihat dari bagaimana memilih fakta. Kedua, bagaimana realitas/dunia dibentuk dilihat dari bagaimana menulis fakta.

\section{Memilih Fakta}

Analisis framing secara sederhana dapat digambarkan sebagai analisis untuk mengetahui bagaimana realitas (peristiwa, aktor, kelompok, atau apa saja) dibingkai oleh media. Realitas sosial dimaknai dan dikonstruksi dengan makna tertentu. Peristiwa dipahami dengan bentukan tertentu. Hasilnya, pemberitaan media pada sisi tertentu atau wawancara dengan orang- orang tertentu. Semua elemen tersebut bukan hanya bagian dari teknis jurnalistik, tetapi menandakan bagaimana peristiwa dimaknai dan ditampilkan.

Berdasarkan keseluruhan hasil framing terhadap berita pawiyatan di rubrik pendidikan surat kabar harian SOLOPOS, peneliti menemukan bahwa rubrik pendidikan surat kabar harian SOLOPOS telah menerapkan kelengkapan berita dan sesuai dengan prosedur yang telah ditepakan seperti menampilkan semua kemungkinan konflik yang muncul, menampilkan fakta-fakta pendukung, pemakaian kutipan pendapat dari narasumber yang sesuai, dan menyusun informasi dalam tata urutan tertentu.

Melalui analisis framing, Peneliti menemukan bahwa artikel berita pawiyatan yang di muat di rubrik pendidikan surat kabar harian SOLOPOS terlihat ada usaha wartawan dan redaktur untuk memberi perbedaan isi berita dengan media lainnya. Perbedaan rubrik pendidikan surat kabar harian SOLOPOS ditunjukkan pada pemilihan berita. Dalam rubrik pendidikan selalu disisipan sub rubrik berita soft news yang berbeda-beda setiap harinya.

Sub rubrik yang terdapat di rubrik pendidikan diantaranya profil siswa berbrestasi, profil guru berprestasi, ekstrakulikuler, bahasa kita, didaktika, dan pawiyatan. Adanya sub rubrik yang disisipkan setiap harinya bertujuan untuk membedakan rubrik pendidikan surat kabar harian SOLOPOS dengan surat kabar lainnya. Cenderung rubrik pendidikan di surat kabar lain seperti WAWASAN, hanya memberitan berita-berita hard news saja, walaupun ada beberapa berita soft 
news tidak ada suatu yang khusus seperti sub rubrik yang ada di surat kabar harian SOLOPOS.

Dalam (Eriyanto, 2002 : 67-69) Todd Gitlin menjelaskan strategi realitas/dunia dibentuk dan disederhanakan sedemikian rupa untuk ditampilkan kepada khalayak pembaca. Peristiwa-peristiwa ditampilkan dalam pemberitaan agar tampak menonjol dan menarik khalayak pembaca. Hal itu dilakukan dengan seleksi, pengulangan, penekanan, dan presentasi aspek tertentu dan realitas.

Menyeleksi berita yang layak dimuat sesuai dengan karakter pawiyatan yaitu lembaga pendidikan yang memiliki keunggulan terutama pada non akademik dari sekolah tersebut yang tidak ada di sekolah lain. Seperti pada kedua berita yang menjadi sampel, terlihat informasi yang ditonjolkan diantaranya yaitu; judul berita dengan jenis teaser dimana membangkitkan rasa ingin tahu dan menghibur pembaca melalui judul, lead di buat ringkas dan tidak lepas dari isi keseluruhan berita, dan body berita dibuat dengan bahasa sederhana.

Pengulangan sub rubrik berita soft news di rubrik pendidikan surat kabar harian SOLOPOS dilakukan setiap hari dengan sub rubrik yang berbeda-beda. Sub rubrik pawiyatan diadakan dengan tujuan memberikan tempat khusus pada lembaga pendidikan untuk mengkatualisasikan kegiatankegian positif baik akademik atau non akademik di sekolah mereka. Berdasarkan tujuan tersebut penekanan $5 \mathrm{~W}+1 \mathrm{H}$ pada sub rubrik berita soft news lebih mengarah pada unsur why (siapa) karena berita pawiyatan ingin memperkenalan kepada masyarakat prestasi dan kegiatan positif di sekolah tersebut.

Menurut Gitlin, frame adalah bagian yang pasti hadir dalam praktik jurnalistik. Dengan frame, jurnalis memproses berbagai informasi yang tersdia dengan mengemasnya sedemikian rupa dalam kategori kognitif tertentu dan disampaikan kepada khalayak. Organisasi media tidak hanya mempunyai struktur dan pola kerja, tetapi juga memiliki ideologi professional.

Nilai berita yang di jadikan standar pembuatan berita pawiyatan adalah Unusual dan proximity. SOLOPOS merupakan surat kabar harian lokal yang target pembacanya adalah warga sekitar Solo sehingga faktor kedekatan sangat diutaman dalam unsur nilai berita pawiyatan. Selain itu, untuk membuat berita yang berbeda dengan surat kabar lain pawiyatan harus memilih berita yang tidak biasa atau jarang terjadi.

Realitas yang dikemukakan pimpinan redaksi akan bertemu dengan realitas subjektif yang terjadi pada saat wartawan melakukan peliputan peristiwa di lapangan. Berita dari wartawan inilah yang akan masuk dalam proses editing oleh redaktur, dan proses kontruksi inilah yang menghasilkan produk berita yang akan diperoleh pembaca. Perbedaan berita versi wartawan dengan redaktur tergantung dari persamaan mereka dalam melihat sebuah bingkai tertentu.

Pada dasarnya kegiatan framing terdiri dari proses memilih dan menulis fakta. Dalam proses ini wartawan hanya menuliskan realitas yang terjadi di lapangan, sedangkan redaktur memiliki wewenang untuk mementukan hasil 
akhir berita. Dalam berbagai proses tersebut, akan masuk berbagai hal yang menjadi landasan berfikir baik dari wartawan, redaktur ataupun media itu sendiri.

Rubrik pendidikan surat kabar harian SOLOPOS menerapkan standar tegas dalam memperoleh berita baik dengan cara reporter menemui langsung narasumber, menghubungi melalui telepon, narasumber menghubungi reporter, ataupun memperoleh informasi melalui siaran pers atau konferensi pers. Semua hal tersebut harus ditulis secara jelas.

Hal tersebut terlihat dari pencantuman lokasi wawancara yang ditulis wartawan di berita "SMKN 9 Terus Tingkatkan Profesionalisme" dan berita "Bekali Siswa SMAN 6 Berwirausaha"yaitu pada pernyataan Sriyadi dan harminingsih dalam bentuk kutipan langsung dari narasumber "..Tujuannya adalah untuk sejenak flash back. Kami ingin melihat apa saja yang telah dilakukan dari tahun ke tahun," ungkap dia kepada Espos di ruang kerjanya, Rabu”, “..Media tanam tersebut berupa tanah dicampur dengan pupuk. "sehingga bisa langsung ditanami," ujar Harminingsih, saat ditemui Espos di ruang kerjanya (7/7)".

\section{Menulis Fakta}

Berdasarkan hasil wawancara yang dilakukan oleh peneliti kepada Muhamad Mufid sebagai redaktur rubrik pendidikan SOLOPOS dan Bayu Jatmiko Aji sebagai reporter rubrik pendidikan SOLOPOS, pembingkaian berita pada rubrik pendidikan surat kabar harian SOLOPOS tidak bisa lepas dari proses memilih dan menulis berita.

SOLOPOS memiliki ketentuanketentuan yang diterapkan sebagai standar penulisan berita. Dalam menulis berita banyak hal yang perlu diperhatikan. Untuk memudahkan wartawan dalam menuliskan berita SOLOPOS memiliki pedoman buku "GAYANe SOLOPOS" yang dijadikan acuan. Semua tentang tata cara penulisan berita mulai dari memilih judul, menulis lead, tubuh berita, kutipan, foto dan caption dijelaskan dalam buku tersebut.

Dalam memilih judul berita harus dapat memaksa orang tertahan untuk membaca seterusnya. Judul tidak bisa lepas dari lead dan tubuh berita karena judul mencerminkan isi dari keseluruhan berita (SOLOPOS, 2006: 23). Sub rubrik Pawiyatan adalah salah satu berita soft news yang setiap hari selasa terbit di rubrik pendidikan SOLOPOS. Judul pada berita pawiyatan "SMKN 9 Terus tingkatkan Profesionalisme" dan "Bekali Siswa SMAN 6 Berwirausaha" termasuk dalam jenis teaser, artinya membangkitkan rasa ingin tahu dan menghibur pembaca melalui judul. Judul untuk berita soft news pada rubrik pendidikan SOLOPOS dibuat lebih santai karena memiliki tujuan untuk menghibur atau memberikan informasi ringan.

Menulis lead memiliki maksud dan tujuan untuk menggoda minat pembaca, menyuguhkan menu terpenting dari berita, membawa pembaca masuk ke rangkaian berikut berita (SOLOPOS, 2006:4).

Dalam berita pawiyatan di rubrik pendidikan surat kabar harian SOLOPOS menggunakan kalimat aktif dan mudah dipahami. Selain itu Lead dalam dua berita tersebut dibuat ringkas dengan tujuan untuk memberi kesempatan kepada pembaca untuk 
mencerna isi dan mengambil keputusan untuk membaca atau tidak sama sekali.

Tubuh berita, dalam berita pawiyatan di rubrik pendidikan surat kabar harian SOLOPOS menggunakan bahasa yang sederhana dengan tujuan agar mudah dimengerti dan dipahami khalayak pembaca. Bahasa yang digunakan adalah bahasa yang santai, ngepop dan istilah jawa tidak tabu dipakai, namun tetap dibatasi penggunaanya dengan tetap mencantumkan istilah atau terjemahannya dalam Bahasa Indonesia.

Dalam pemberitaan sub rubrik pawiyatan pada rubrik pendidikan surat kabar harian SOLOPOS, penggunaan foto dan caption berita digunakan untuk memberi penekanan dalam pemberitaan. Foto yang di ambil dalam berita pawiyatan adalah gedung sekolah dari SMKN 9 Solo dan SMAN 6 Solo. Melalui foto dan caption, pembaca dapat menerima informasi yang diharapkan. Caption merupakan keterangan ringkas dan jelas dari sebuah foto untuk memberi kesatuan informasi yang utuh.

Upaya pembingkaian yang dilakukan oleh SOLOPOS terlihat masih menjaga netralis dan objektivitas dalam menyampaikan berita. Hal tersebut misalnya dapat dilihat dari kelengkapan unsur $5 \mathrm{~W}+1 \mathrm{H}$. Selain itu, SOLOPOS memasukan sumber-sumber yang kompeten mengenai berita pawiyatan di rubrik pendikan surat kabar harian SOLOPOS.

Unsur $5 \mathrm{~W}+1 \mathrm{H}$ yang tertulis lengkap di dalam surat kabar harian SOLOPOS. Hal ini menunjukan tingkat keakuratan yang dapat dipertanggung jawabkan secara jurnalistik. Secara tidak langsung SOLOPOS ingin menunjukan bahwa informasi dari pemberitaan sub rubrik pawiyatan pada rubrik pendidikan menginformasikan keunggulan non akademik suatu lembaga pendidikan dengan maksud mempromosikan ataupun memperkenalkan sekolah-sekolah yang ada di Solo. Hal ini berdampak positif bagi masyarakat terutama lembagalembaga pendidikan yang ada di Solo.

Beberapa lembaga pendidikan baik negeri atau swasta ada yang meminta untuk diliput kegiatan mereka dengan cara menghubungi langsung wartawan pendidikan SOLOPOS. Selain itu dengan adanya sub rubrik pawiyatan di rubrik pendidikan surat kabar harian SOLOPOS masyarakat Solo mendapat referensi untuk memilih sekolah mana yang dapat dijadikan pilihan bagi keluarga mereka untuk menuntut ilmu. Dari hal tersebut terlihat bahwa masyarakat percaya akan keakuratan isi berita di surat kabar harian SOLOPOS.

\section{Kesimpulan}

Berdasarkan penelitian yang telah dilakukan, dapat ditarik kesimpulan bahwa pembingkaian berita di rubrik pendidikn surat kabar harian SOLOPOS menampilkan keunikan sebagai pembeda dengan media lain untuk menarik perhatian pembaca. Hal tersebut terlihat dengan adanya sub rubrik yang berbeda-beda disisipkan setiap hari, salah satunya yaitu sub rubrik pawiyatan.

Upaya pembingkaian yang dilakukan oleh rubrik pendidikan surat kabar harian SOLOPOS setelah dilakukan analisis framing model Todd Gitlin, terdapat dua aspek yang diutamakan dalam pembingkaian. Pertama yaitu bagaimana memilih fakta untuk ditonjolkan agar layak menjadi berita pawiyatan. Kedua, bagaimana menulis 
fakta untuk ditampilkan kepada khalayak.

Fakta yang dipilih harus memiliki nilai berita yang menonjolkan pada proximity (kedekatan) dan unusual (peristiwa yang jarang trerjadi). Kedua nilai berita tersebut dipilih karena surat kabar harian SOLOPOS merupakan surat kabar harian lokal yang target pembacanya adalah masyarakat Solo dan sekitarnya, sehingga proximity (kedekatan) menjadi nilai berita utama yang diterapkan untuk berita pawiyatan.

Sedangkan Unusual (peristiwa yang jarang terjadi) dipilih karena sub rubrik pawiyatan adalah berita yang terbit seminggu sekali, dan isi berita yang ditonjolkan adalah keunggulan sebuah lembaga pendidikan yang berbeda dari lembaga pendidikan lain sehingga informasi yang dicari adalah peristiwa dan kegiatan yang unik dan jarang trerjadi atau belum pernah terjadi.

Berkaitan dengan penulisan fakta pada rubrik pendidikan surat kabar harian SOLOPOS memiliki ketentuanketentuan yang diterapkan sebagai standar penulisan berita. Semua strandar penulisan berita terdapat dalam buku pedoman GAYANe SOLOPOS. Berkaiatan dengan berita pawiyatan, penulisan berita menggunakan bahasa yang sederhana, menggunakan gaya penulisan piramida terbalik dimodifikasi.

Selain itu terlihat bahwa surat kabar harian SOLOPOS masih menjaga netralitas dan obyektifitas dalam menyampaikan berita. Hal ini dapat dilihat dari kelengkapan unsur $5 \mathrm{~W}+$ 1H. Selain itu, rubrik pendidikan surat kabar harian SOLOPOS juga memasukkan narasumber yang sesuai dan dapat dipertanggung jawabkan keakuratannya.

Dalam pemberitaannya rubrik pendidikan surat kabar harian SOLOPOS pada bulan Juli 2014 tepatnya saat mendekati penerimaan siswa baru berimbang dalam menyajikan berita pada sub rubrik pawiyatan.

Walaupun isi dari berita pawiyatan menonjolkan sisi keunikan, kelebihan akademik dan non akademik kegiatan pada suatu lembaga pendidikan, tetapi tidak membandingbandingkan atau memberitakan kelemahan dari lembaga pendidikan lainnya.

Sub rubrik yang terdapat di rubrik pendidikan diantaranya profil siswa berprestasi, profil guru berprestasi, ekstrakulikuler, bahasa kita, didaktika dan pawiyatan. Adanya sub rubrik yang disisipkan setiap harinya bertujuan untuk membedakan rubrik pendidikan surat kabar harian SOLOPOS dengan surat kabar lainnya.

Cenderung rubrik pendidikan di surat kabar lain seperti WAWASAN, hanya memberitan berita-berita hard news saja, walaupun ada beberapa berita soft news tidak ada suatu yang khusus seperti sub rubrik yang ada di surat kabar harian SOLOPOS.

\section{Daftar Pustaka}

Eriyanto. 2002. Analisis Framing Konstruksi, Ideologi, dan Politik Media. Yogyakarta: LKiS. H. B. Sutopo. 2002.

Muhammad Budyatna. 2009. Jurnalistik Teori dan Praktek. Bandung: PT Remaja Rosdakarya. 
Shoemaker, Pamela J. 2009.

Gatekeeping Theory: Man Hall, California: Routledge Chap.

Sugiyono. 2008. Metode Penelitian

Kuantitatif Kualitatif Dan $R \& D$.

Bandung: Alfabeta.

Tom E. Rolnicki et. al. 2008. Pengantar

Dasar Jurnalisme (Scholastic

Journalism). Jakarta: Kencana.

Utomo Mulyanto. 2007. Solopos Satu

Dasawarsa Meningkatkan

DinamikaMasyarakat. Solo: Griya Solopos.

Solopos. 2006. Gayane Solopos

Panduan Menulis Berita. Solo:

Griya Solopos. 